\title{
Methods in 2012, part 2
}

Nathan S. Blow, PhD.

Editor-in-Chief, BioTechniques

W e received a letter in early May from a long-time reader of BioTechniques. The writer wanted to bring our attention to an article published in BioTechniques in 2010 on an overlap extension PCR cloning method (I) which appeared to be similar to that of a 200 I article (2). The letter writer was rightthere were common threads between the two techniques. However, it was the opinion of the editors that the 2010 article presented a more easily implementable procedure for overlap PCR cloning than the 2001 article.

Although in agreement on the merits of the 2010 overlap PCR cloning article, the letter did stir up spirited debate among the editors - when it comes to considering techniques or methods manuscripts, how much room should there be for those articles that make it easier to execute an established technique? And how do we define "easier"? Our author guidelines clearly state that articles must present a "novel method" or "substantive advance upon an existing method" for consideration. While novelty is often easy to assess, when it comes to a "substantive advance upon an existing method" opinions can be varied. Cost savings and speed might seem obvious to some, but everything has tradeoffs, so what might be important for one lab (lower cost), might not be important for another (speed regardless of cost). Compared to the 2001 overlap PCR cloning paper, the 2010 method clearly presented results demonstrating the incorporation of significantly larger pieces of DNA, better efficiency, and the use of a single enzyme for all steps, thereby making the procedure less demanding technically. Could the 2001 approach have worked with larger DNA pieces? Potentially. Could the single enzyme (not available in 2001) be substituted into the 2001 protocol to obtain a more efficient methodology? Again, potentially. But in the end, we, as well as the reviewers, thought the modifications presented in the 2010 article had the potential to enhance the adoption of overlap extension PCR cloning in a variety of fields and therefore warranted publication.

Another question that was raised is whether or not changes/modification to an existing technique would be better suited to the methods section of longer, non-methods articles. During this part of the discussion, I thought about last month's editorial wherein I commented on the shrinking use of methods sections and the continued move by journal publishers to place the methods sections of their articles in online supplementary materials. For me, this seems to be an unfortunate trend that will ultimately make expanding upon current and past studies more difficult for everyone, not to mention limit the access of researchers to incremental methods advances, such as in the overlap PCR cloning case. If the method is removed from the main text, readers are also missing out on the beauty and ingenuity that goes into developing a new method or the systematic evaluation that goes along with enhancing an existing one. It is crucial that authors take the time, and the effort, to clearly document their methods and technical approaches, whether it is for a research article or an article submitted to a methods-specific journal.

In the end, readers will from time to time take issue with the scope or novelty of the methods published in BioTechniques. For us, the goal is to deliver techniques or tools that enhance research in the lab. In the case of overlap PCR cloning, our internal discussions reinforced for us the need to carefully evaluate all articles describing a "substantive advance" - not only at the initial stage of review, but also when reviewers render their decisions, because what one reviewer might see as unnecessary or a small incremental advance in the lab, another will use on a daily basis. As always, please share your thoughts with us by posting at our Molecular Biology Forums under "To the Editor" (http://molecularbiology. forums.biotechniques.com) or sending an email directly to the editors (bioeditor@biotechniques.com).

\section{References}

1. Bryksin, A.V. and Matsumura, I. (2010) Overlap extension PCR cloning: a simple and reliable way to create recombinant plasmids. BioTechniques 48: 463-465.

2. Geiser, M. et al. (2001) Integration of PCR fragments at any specific sites within cloning vectors without the use of restriction enzymes and DNA ligase. BioTechniques 31, 88-92.

BioTechniques 53:11 (July 2012) doi 10.2144/000113882

To purchase reprints of this article, contact:

biotechniques@fosterprinting.com 